\title{
Clinical and Hospital Factors Affecting Treatment with Primary Prevention Implantable Cardioverter- Defibrillators in Ischemic Cardiomyopathy Patients
}

\author{
Jae-Hyuk Lee ${ }^{1 *}$, Hee Tae Yu ${ }^{*}$, Il-Young Oh², Eue-Keun Choi ${ }^{3}$, Jung-Hoon Sung ${ }^{4}$, Young Soo Lee ${ }^{5}$, \\ Jong-Youn $\mathrm{Kim}^{6}$, Yongsoo Baek ${ }^{7}$, Junbeom Park ${ }^{8}$, and Boyoung Joung ; ADVANCE-ICM investigators \\ ${ }^{1}$ Division of Cardiology, Department of Internal Medicine, Yonsei University Health System, Seoul; \\ ${ }^{2}$ Division of Cardiology, Department of Internal Medicine, Seoul National University Bundang Hospital, Seongnam; \\ ${ }^{3}$ Division of Cardiology, Department of Internal Medicine, Seoul National University Hospital, Seoul; \\ ${ }^{4}$ Division of Cardiology, Department of Internal Medicine, CHA Bundang University Hospital, Seongnam; \\ ${ }^{5}$ Division of Cardiology, Department of Internal Medicine, Daegu Catholic University Hospital, Daegu; \\ ${ }^{6}$ Division of Cardiology, Department of Internal Medicine, Gangnam Severance Hospital, Seoul; \\ ${ }^{7}$ Division of Cardiology, Department of Internal Medicine, Inha University Hospital, Incheon; \\ ${ }^{8}$ Division of Cardiology, Department of Internal Medicine, Ewha Womans University Hospital, Seoul, Korea.
}

\begin{abstract}
Purpose: Implantable cardioverter defibrillators (ICD) are the standard of care for primary prevention (PP) in patients with ischemic cardiomyopathy (ICM). However, PP ICD implantation is underused in Asian countries. This study investigated ICD implantation rates and factors associated with appropriate PP ICD implants for ICM.

Materials and Methods: In this prospective multicenter observational registry (ADVANCE-ICM registry), ICM patients who were eligible for PP ICD were screened and enrolled. Factors associated with appropriate ICD implantation, including hospital and clinical factors, were investigated.

Results: Of the 1453 ICM patients eligible for PP ICD [1111 male; median age, 71.0 (61.0-78.0) years], only 76 (5.2\%) patients underwent ICD implantation. Among hospital factors, a non-monetary incentive for referral $(72.4 \%$ vs. $52.9 \%, p=0.001)$ and total hospital system score (6.0 vs. 5.0, $p=0.013$ ) were higher in the ICD than in the no-ICD group. In multivariate analysis, total hospital system score [odds ratio (OR), 1.28; 95\% confidence interval (CI), 1.10-1.50] was an independent factor for predicting ICD implantation, along with clinical factors, including high New York Heart Association class ( $\geq \mathrm{III}$ : OR, 7.29; 95\% CI, 2.97-17.87) and younger age ( $<70$ years: $\mathrm{OR}, 2.14$; $95 \% \mathrm{CI}, 1.30-3.53$ ).

Conclusion: PP ICD implantation for ICM patients is underused in Korea. Hospital factors were important for improving PP ICD implantation rate, suggesting that new screening and referral systems for ICM patients would improve the PP ICD implantation rate (Clinical trial registration No. NCT03590925).
\end{abstract}

Key Words: Defibrillators, implantable; myocardial ischemia; primary prevention

Received: May 29, 2020 Revised: September 19, 2020 Accepted: September 29, 2020

Co-corresponding authors: Boyoung Joung, MD, PhD, Division of Cardiology, Department of Internal Medicine, Severance Cardiovascular Hospital, Yonsei University College of Medicine, 50-1 Yonsei-ro, Seodaemun-gu, Seoul 03722, Korea.

Tel: 82-2-2228-8460, Fax: 82-2-393-2041, E-mail: cby6908@yuhs.ac and

Junbeom Park, MD, PhD, Division of Cardiology, Department of Internal Medicine, Ewha Womans University Hospital, 1071 Annyangcheon-ro, Yangcheon-gu, Seoul 07985, Korea.

Tel: 82-2-2650-5826, E-mail: parkjb@ewha.ac.kr

*Jae-Hyuk Lee and Hee Tae Yu contributed equally to this work.

-Dr. Boyoung Joung has served as a speaker for Bayer, BMS/Pfizer, Medtronic, and Daiichi-Sankyo and has received research funds from Medtronic and Abbott. None of the other authors have any disclosures to make. No fees were directly received personally.

(C) Copyright: Yonsei University College of Medicine 2020

This is an Open Access article distributed under the terms of the Creative Commons Attribution Non-Commercial License (https://creativecommons.org/licenses/by-nc/4.0) which permits unrestricted non-commercial use, distribution, and reproduction in any medium, provided the original work is properly cited. 


\section{INTRODUCTION}

Heart failure (HF) patients with a reduced left ventricular ejection fraction (LVEF) are at increased risks for arrhythmic events and sudden cardiac death, ${ }^{1}$ and its prevention has been a clinical subject of interest for more than 25 years. ${ }^{2} \mathrm{Im}$ plantable cardioverter defibrillator (ICD) device therapy has been shown to reduce the risk of sudden cardiac death and allcause mortality in primary ${ }^{3-5}$ and secondary prevention..$^{6-9}$ The guidelines of the European Society of Cardiology ${ }^{10,11}$ and the American College of Cardiology Foundation/American Heart Association ${ }^{12,13}$ give class 1 recommendations for implantation of ICD devices for primary prevention (PP) in symptomatic [New York Heart Association (NYHA) functional class II, III] HF patients with a LVEF $\leq 35 \%$ despite optimal medical therapy for more than 3 months.

Randomized clinical trials have shown a mortality benefit from PP ICD in patients at high risk of sudden cardiac death. ${ }^{3,4,14-16}$ Indications for PP ICD implantation in Korea were published in 2008 and revised in 2016. The Korean indication guidelines for PP ICD implantation in ischemic cardiomyopathy (ICM) are as follows: 1 ) $\mathrm{LVEF} \leq 30 \%$ [at least 40 days post-myocardial infarction (MI)]; 2) LVEF 31-35\%, NYHA class II, III (at least 40 days post-MI); and 3) LVEF $\leq 40 \%$, non-sustained ventricular tachycardia, and inducible ventricular fibrillation or sustained ventricular tachycardia on an electrophysiological study (at least 40 days post-MI). Despite these well-publicized guidelines, implant rates are lower than national targets, and PP ICD accounts for only a minority of implants in Korea.

Despite extensive clinical trial evidence and recommendations in national guidelines, treatment guidelines are adopted slowly in Asian countries and applied inconsistently. ${ }^{17}$ Poor guideline adherence often fails to lead to improvements in patient care quality and outcomes. ${ }^{18-24}$ The reasons for low PP implant rates are likely to be multifactorial and include a lack of physician knowledge (particularly non-implanting cardiologists); failure to implement guidelines; failure to screen patients and collect relevant data, such as LVEF; a lack of financial resources or available implanting cardiologists; age, sex, or race bias; or even patient refusal to accept therapy. For hospitalized HF patients and outpatients, gaps, variations, and disparities between evidence-based guideline recommendations and actual treatments provided have been documented. ${ }^{18-24}$ The underuse of ICD and cardiac resynchronization therapy with a defibrillator is an issue in Asian countries. ${ }^{25-29}$ Collaboration between interventionists and electrophysiologists may facilitate ICD implantation in eligible patients. This study investigated ICD implantation rates and factors associated with appropriate PP ICD implants for ICM using data from a prospective multicenter registry.

\section{MATERIALS AND METHODS}

\section{Study design}

The Evaluation of the Improvement of Primary Prevention in Ischemic Cardiomyopathy patients using new screening and referral systems (ADVANCE-ICM) is a prospective multicenter observational study of patients aged $>18$ years and $<90$ years with ICM and an LVEF $\leq 40 \%$ who were attending any of the 12 tertiary centers encompassing all geographical regions of Korea. The study enrollment period started in July 2018 and will end in June 2021.

The aim of the ADVANCE-ICM study is to evaluate the effect of the new screening and referral systems to improve PP in ICM patients through a prospective, non-randomized, nonblinded, observational, multicenter design. Patients were enrolled in this study if they were eligible for ICD implantation for PP with ICM and offered adequate treatment regardless of actual ICD implantation. Patients who underwent ICD implantation for PP of sudden cardiac death with severe LV dysfunction due to ICM during follow-up period were evaluated. Indications for ICD implantation for PP were according to the 2016 revised Korean indication guidelines. The data collection was usually conducted by personnel with no clinical activity assigned to the project. The data were entered into a common electronic database that limits inconsistencies and errors and provides online help for key variables. The study staff at each center could see their own center's data and the data from all other participating centers.

The study was approved by the ethics committees of each center, and all patients provided informed consent for their inclusion (IRB number: 4-2018-0075). The study complied with the ethical rules of the Declaration of Helsinki as a statement of ethical principles for medical research involving human subjects by the World Medical Association. We followed all ethical, scientific, and medical standards that protect the rights of participants and required informed consent from all study participants and review and approval of study protocols, including patient information forms, from respective ethics committees: Severance Hospital, Seoul National University Hospital, Korea University Medical Center, Daegu Catholic University Medical Center, Ewha Womans University Medical Center, Kyung Hee University Hospital, Inha University Hospital, Gangnam Severance Hospital, CHA Bundang Medical Center, Seoul St. Mary's Hospital, Seoul National University Bundang Hospital, and Wonju Severance Hospital. This study was registered at ClinicalTrials.gov (NCT03590925).

Among the 12 hospitals, three started enrollment late because of delayed IRB approval or late participation in this study. For accurate results, we analyzed the data of patients from nine hospitals. A total of 1453 ICM patients with PP ICD indications were enrolled in the ADVANCE-ICM registry from July 2018 to February 2020. Among them, ICD was implanted in 76 patients (ICD group), but not in 1377 patients (no-ICD group). 


\section{Patient factors}

Age; sex; body mass index; medical histories of hypertension, diabetes mellitus, valvular heart disease, congestive HF, peripheral arterial occlusive disease (PAOD), stroke or transient ischemic attack, dyslipidemia, chronic kidney disease, malignancy, and bleeding; NYHA class; prescribed medication; and echocardiographic parameters, such as LVEF, left atrial (LA) anteroposterior diameter, LA volume index, and E/Em, were obtained from medical records at the time of enrollment.

\section{Hospital factors}

Hospital factors of each center associated with ICD implantation were evaluated by a questionnaire. Total hospital system score was defined as the sum of the number of applied systems, including multidisciplinary conference, non-monetary incentive for referral, automated notice system, patient education system, patient brochure, HF clinic, and ICD check-up clinic. Non-monetary incentive for referral was defined as a reward system for encouraging physicians to refer patients to electrophysiology doctors. The term 'non-monetary incentive' in this paper does not mean economic rewards or compensation, but a recognition of medical performance or clinical achievement. The automated notice system was a computerized system that automatically shows a pop-up memo to physicians when patients who are eligible for ICD implantation visit the outpatient clinic.

\section{Statistical analysis}

Continuous variables are presented as medians [interquartile range (IQR)] for non-normally distributed value, and categorical variables are shown as numbers and percentages in each group. Continuous and categorical variables were compared using the Wilcoxon rank-sum test and Fisher's exact test, respectively. To investigate factors associated with appropriate ICD implantation, univariate and multivariate logistic regression were employed, and odds ratio (OR), 95\% confidence intervals (CI), and $p$ values were determined. Since system factors have multicollinearity, total hospital system score was used as the system factor in the multivariate logistic regression analysis. Additional analyses to elucidate characteristics among centers were performed based on a questionnaire and information of each center using Kruskal-Wallis test and Fisher's exact tests. Two-sided $p$ values $<0.05$ were considered statistically significant. The Statistical Package for the Social Sciences version 25.0 for Windows (IBM Corporation, Armonk, NY, USA) and R software version 3.6.2 (The R foundation for Statistical Computing, Vienna, Austria) were employed in the data analysis.

\section{RESULTS}

\section{Baseline clinical characteristics}

A total of 1453 ICM patients [1111 male, median age 71.0 (61.0-
78.0) years] eligible for PP ICD were enrolled in the ADVANCEICM registry from July 2018 to February 2020. Among them, ICD was implanted in 76 patients during 11 (IQR, 7-12) months of follow-up. The patients in the ICD group were significantly younger (67.0 years vs. 71.0 years, $p=0.002$ ), had a higher ( $\geq \mathrm{III})$ NYHA functional class ( $10.5 \%$ vs. $2.8 \%, p<0.001)$, had a lower LVEF (29.0\% vs. $31.0 \%, p<0.001$ ), and were taking more angiotensin converting enzyme inhibitor (ACEi)/angiotensin receptor antagonist (ARB) and antiarrhythmic agents than patients in the no-ICD group (Table 1).

\section{Hospital factors}

The detailed applied systems for advancing ICD implantation in each center and the characteristics of the nine tertiary centers, including hospital bed supply, number of electrophysiologists, absolute ICD implantation number, ICD implantation rate, and referral rate for ICD implantation from other parts, are shown in Supplementary Table 1 (only online).

To elucidate the effect of hospital size on ICD implantation, the centers were divided into three groups according to the number of hospital beds as a marker of hospital size (group 1, $\geq 1200$ beds; group $2, \geq 850$ but $<1200$ beds; and group $3,<850$ beds). Groups 1 and 2 had significantly higher total hospital system scores than group 3 (group 1 vs. group $3, p=0.046$; group 2 vs. group 3, $p=0.043$ ) (Fig. 1A). The absolute number of ICD implantations was higher in group 1 than groups 2 and 3 (group 1 vs. group 2, $p=0.043$; group 1 vs. group 3, $p=0.046$ ) (Fig. 1B). However, ICD implantation rate did not differ significantly among the three groups (Fig. 1C). To investigate factors affecting the ICD implantation rate in the larger (group 1) and smaller (group 3) centers, the centers' characteristics were reviewed. A higher referral rate was noted in centers with higher ICD implantation rates (Supplementary Table 1, only online). To evaluate the effects of the referral rate, centers were divided into two groups according to their referral rates (group $A, \geq 30 \%$; group B, <30\%). Group A had significantly higher total hospital system scores than group B (group A vs. group B; $p=0.032$ ) (Fig. 2A). Group A also had a significantly higher number of absolute ICD implantations than group B (group A vs. group B; $p=0.032$ ) (Fig. 2B). However, ICD implantation rate did not differ between the two groups (group A vs. group B; $p>0.999$ ) (Fig. $2 \mathrm{C}$ ). Instead, additional analysis of the association between individual hospital factors with ICD implantation rate revealed that ICD implantation rates were higher in hospitals that applied non-monetary incentives for referral systems than hospitals that did not ( $p=0.016$ ) (Fig. 3).

Table 2 shows a comparison hospital system factors between the ICD and no-ICD groups. Among hospital factors, a nonmonetary incentive for referral $(72.4 \%$ vs. $52.9 \%$; $p=0.001)$ and total hospital system score ( 6.0 vs. $5.0 ; p=0.013)$ were higher in the ICD group than in the no-ICD group (Table 2). 
Jae-Hyuk Lee, et al.

Table 1. Baseline Clinical and Echocardiographic Parameters in the ICD and No-ICD Groups

\begin{tabular}{|c|c|c|c|c|}
\hline & All subjects ( $n=1453$ ) & ICD group ( $n=76)$ & No-ICD group ( $\mathrm{n}=1377$ ) & $p$ value \\
\hline Age (yr) & $71.0(61.0-78.0)$ & $67.0(59.0-72.5)$ & $71.0(61.0-78.0)$ & 0.002 \\
\hline Male & $1111(76.5)$ & $60(78.9)$ & $1051(76.3)$ & 0.700 \\
\hline $\mathrm{BMI}\left(\mathrm{kg} / \mathrm{m}^{2}\right)$ & $23.5(21.3-25.7)$ & $24.4(21.6-26.0)$ & $23.5(21.3-25.7)$ & 0.076 \\
\hline Hypertension & 942 (64.8) & $50(65.8)$ & 892 (64.8) & 0.955 \\
\hline Diabetes mellitus & $720(49.6)$ & $37(48.7)$ & $683(49.6)$ & 0.970 \\
\hline Valvular heart disease & $275(18.9)$ & $11(14.5)$ & 264 (19.2) & 0.386 \\
\hline Congestive heart failure & $1305(89.8)$ & 68 (89.5) & 1237 (89.8) & $>0.999$ \\
\hline PAOD & $847(58.3)$ & $36(47.4)$ & $811(58.9)$ & 0.062 \\
\hline Stroke/TIA & $195(13.4)$ & $8(10.5)$ & $187(13.6)$ & 0.557 \\
\hline Dyslipidemia & $881(60.6)$ & $39(51.3)$ & $842(61.1)$ & 0.112 \\
\hline Chronic kidney disease & $351(24.2)$ & $19(25.0)$ & $332(24.1)$ & 0.969 \\
\hline Malignancy & $83(5.7)$ & $3(3.9)$ & $80(5.8)$ & 0.669 \\
\hline Bleeding history & $47(3.2)$ & $3(3.9)$ & $44(3.2)$ & 0.978 \\
\hline \multicolumn{5}{|l|}{ NYHA functional class } \\
\hline Class I, II & 1407 (96.8) & $68(89.5)$ & $1339(97.3)$ & $<0.001$ \\
\hline Class III, IV & $46(3.2)$ & $8(10.5)$ & $38(2.8)$ & $<0.001$ \\
\hline $\operatorname{LVEF}(\%)$ & $31.0(26.0-35.0)$ & $29.0(25.0-32.0)$ & $31.0(26.0-35.0)$ & $<0.001$ \\
\hline LA AP diameter (mm) & $44.0(39.0-49.0)$ & $43.9(36.3-57.6)$ & $43.7(32.5-56.8)$ & 0.266 \\
\hline LA volume index $\left(\mathrm{mL} / \mathrm{m}^{2}\right)$ & 43.8 (32.8-56.8) & $45.0(40.0-49.0)$ & $44.0(39.0-49.0)$ & 0.644 \\
\hline $\mathrm{E} / \mathrm{Em}$ & $15.5(11.4-22.5)$ & $14.0(10.5-21.7)$ & $15.5(11.5-22.5)$ & 0.301 \\
\hline \multicolumn{5}{|l|}{ Medication } \\
\hline ACEi/ARB & 1119 (81.3) & $68(91.9)$ & $1051(80.7)$ & 0.025 \\
\hline Beta blocker & $1096(79.7)$ & 66 (89.2) & $1030(79.1)$ & 0.052 \\
\hline Aldosterone antagonist & $684(49.7)$ & $44(59.5)$ & $640(49.2)$ & 0.108 \\
\hline Anticoagulant & $301(21.9)$ & $19(25.7)$ & $283(21.7)$ & 0.514 \\
\hline Diuretics & $753(54.7)$ & 48 (64.9) & $705(54.1)$ & 0.093 \\
\hline Statin & $1095(79.6)$ & $63(85.1)$ & 1032 (79.3) & 0.284 \\
\hline Antiplatelet & $1130(82.1)$ & $56(75.7)$ & $1074(82.5)$ & 0.183 \\
\hline Antiarrhythmic agent & $65(4.7)$ & $8(10.8)$ & $57(4.4)$ & 0.024 \\
\hline CCB & $152(11.0)$ & $8(10.8)$ & $144(11.1)$ & $>0.999$ \\
\hline
\end{tabular}

ACEi, angiotensin converting enzyme inhibitor; AP, anteroposterior; ARB, aldosterone receptor blocker; BMI, body mass index; CCB, calcium channel blocker; E/ Em, ratio of mitral valve inflow and tissue doppler; ICD, implantable cardioverter defibrillator; LA, left atrial; LVEF, left ventricular ejection fraction; NYHA, New York Heart Association; PAOD, peripheral arterial occlusive disease; TIA, transient ischemic attack.

Values are presented as a median [01-03 quartiles (25th and 75th percentiles)] or number (\%).

\section{Factors associated with appropriate ICD implantation} In univariate analysis, age $<70$ years, absence of a history of PAOD; taking ACEi/ARB, beta blocker, or antiarrhythmic agents; severe NYHA functional class (III and IV) were significantly associated with appropriate ICD implantation [Table 3 and Supplementary Table 2 (only online)]. Due to multicollinearity among the applied systems, total hospital system score was used to represent hospital systems, and the score was significantly high in the ICD group. The univariate analysis results of all variables are shown in Supplementary Table 2 (only online).

Multivariate analysis was performed with adjustment for age $<70$ years; presence of PAOD; NYHA functional class (III and IV); taking ACEi/ARB, beta blocker, and antiarrhythmic agents; and total hospital system score. Total hospital system score
(OR, 1.28; 95\% CI, 1.10-1.50) was an independent factor predictive of ICD implantation with clinical factors, including high NYHA class ( $\geq$ III: OR, 7.29; 95\% CI, 2.97-17.87) and younger age (<70 years: OR, 2.14; 95\% CI, 1.30-3.53) (Table 3 ).

\section{DISCUSSION}

\section{Main findings}

The main findings of the present study are as follows: 1) the ICD implantation rate for PP for ICM in nine tertiary centers in Korea was only $5.23 \%$; 2) age $<70$ years, absence of history of PAOD, taking antiarrhythmic agents, NYHA functional class III and IV, and high total hospital system scores were associated with appropriate ICD implantation; and 3) larger centers 


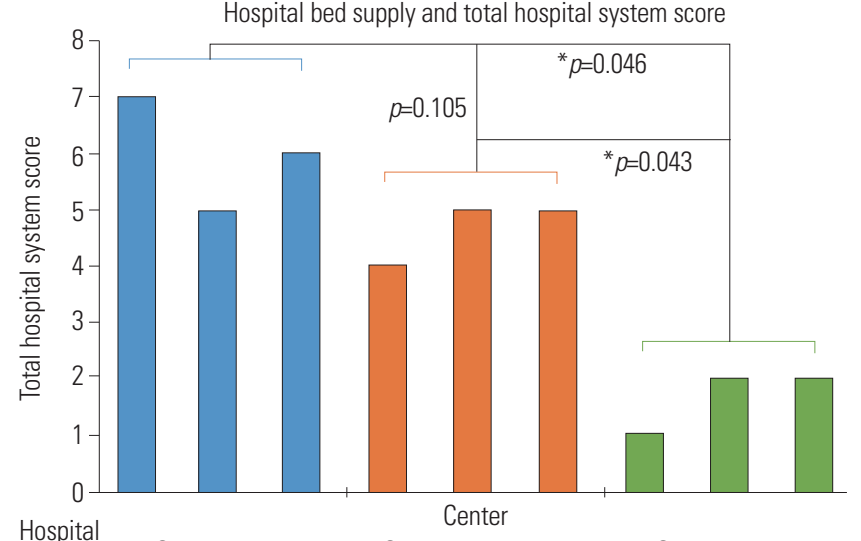

bed supply Group 1. $\geq 1200 \quad$ Group 2. 850-1200 Group 3. $<850$

A

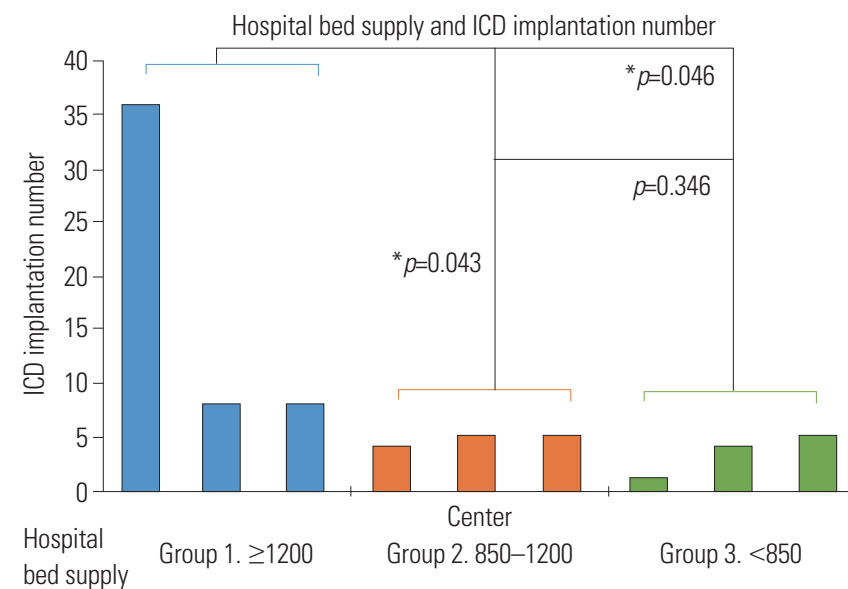

B

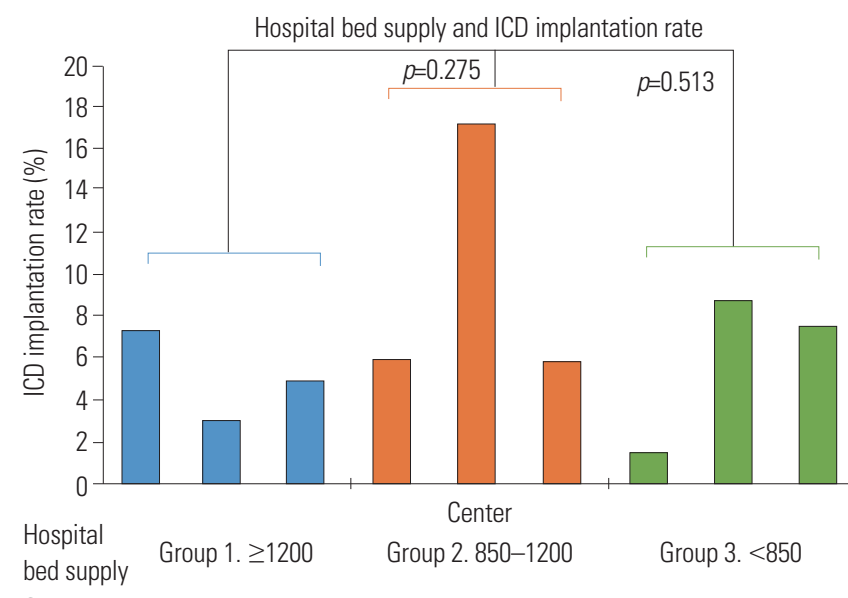

C

Fig. 1. Associations between center size and total hospital system score, ICD implantation number, and ICD implantation rate. (A) Large centers (groups 1 and 2) applied more systems for improving ICD implantation than relatively small centers (group 3). (B) Large centers (group 1) also implanted higher numbers of ICDs than smaller centers (group 2 and 3 ). (C) However, ICD implantation rate did not differ according to center size. ICD, implantable cardioverter defibrillator.

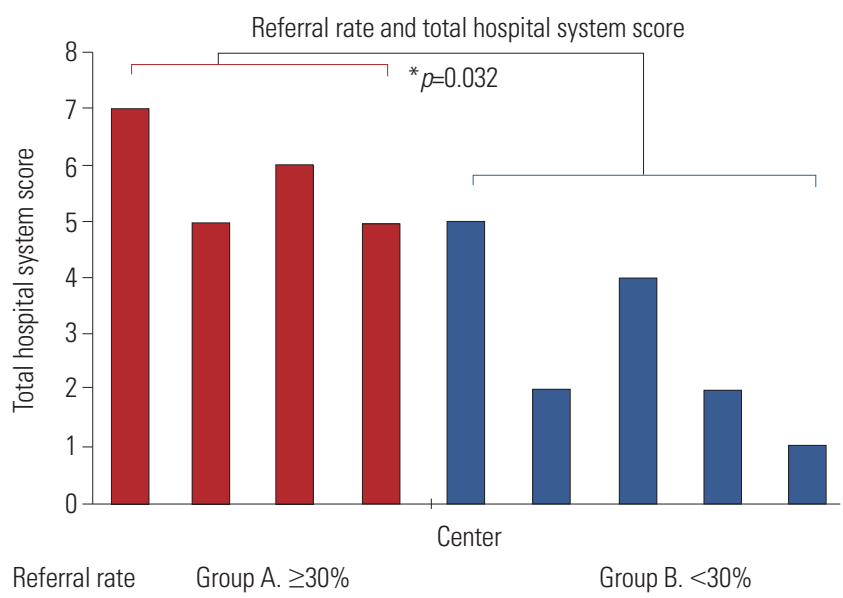

A

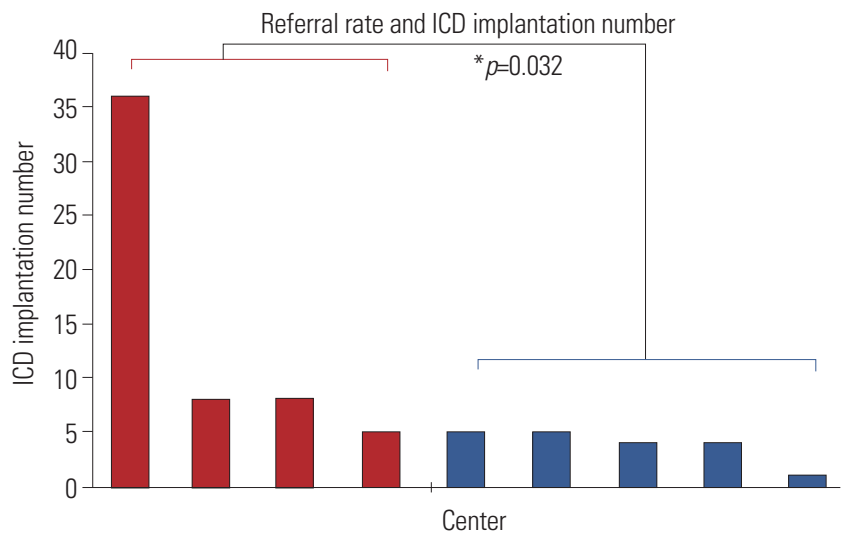

Referral rate Group A. $\geq 30 \% \quad$ Group B. $<30 \%$

B

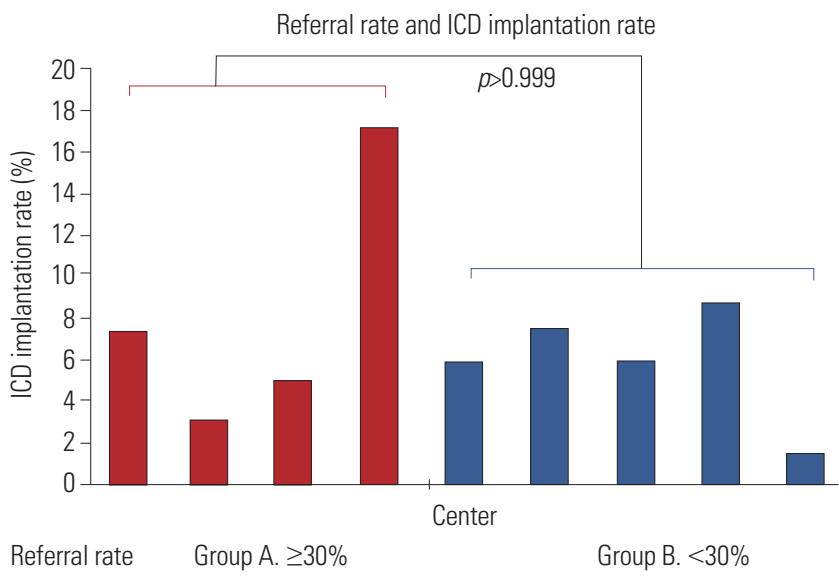

C

Fig. 2. Associations between referral rate and total hospital system score, ICD implantation number, and ICD implantation rate. (A) Centers with a high referral rate from other departments (group A) applied more systems than centers with a low referral rate (group B). (B) Furthermore, centers with a high referral rate (group A) implanted more ICD implantations than centers with a low referral rate (group B). (C) However, ICD implantation rate did not differ according to referral rate. ICD, implantable cardioverter defibrillator. 


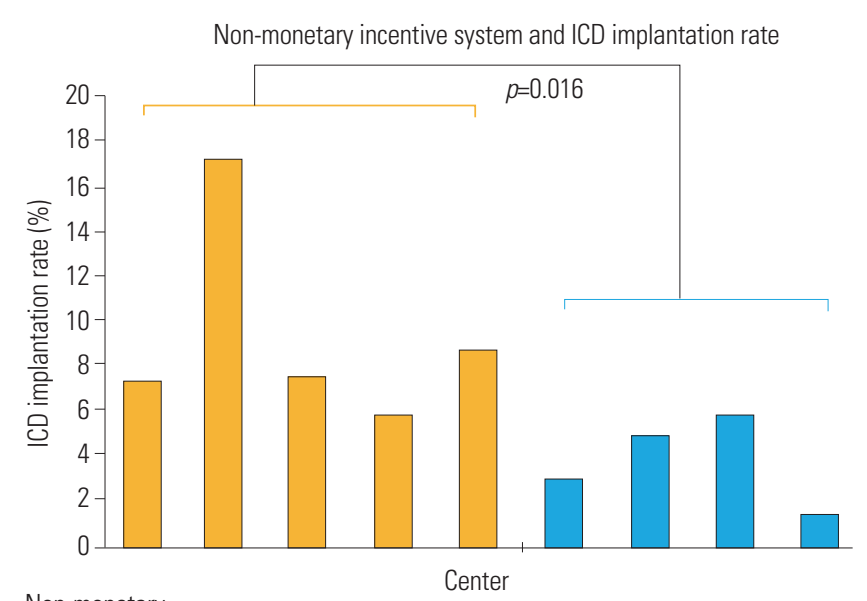

Non-monetary incentive for Applying hospitals Not applying hospitals referral

Fig. 3. Association between non-monetary incentive systems and ICD implantation rate. ICD implantation rates were higher in centers that applied non-monetary incentive systems than in those that did not. ICD, implantable cardioverter defibrillator. and centers with higher referral rates applied more hospital systems for improving ICD implantation and implanted more absolute numbers of PP ICDs. However, implantation rate did not differ significantly according to the sizes or referral rates for each hospital. Instead, implantation rates differed significantly according to the application of a non-monetary incentive for referral systems.

\section{Discordant practice in PP ICD}

Despite the existence of evidence-based and well-established national guidelines, PP ICD implant rates vary among countries and are low in Asian countries. ${ }^{17,29}$ Previous studies reported that PP ICD implantation rates for eligible patients were $10 \%, 60 \%$, and 5\% in Sweden, US, and an Asian country, respectively. ${ }^{25,26,29}$ The present study showed that only $5.23 \%$ of patients who were eligible for PP ICD were treated with ICDs. We could not evaluate whether electrophysiology study was performed in patients whose LVEF was over $35 \%$ according to guidelines because of the multicenter study design. Instead,

Table 2. Baseline Hospital Factors Related to ICD Implantation in the ICD and No-ICD Groups

\begin{tabular}{|c|c|c|c|c|}
\hline & All subjects ( $n=1453)$ & ICD group (n=76) & No-ICD group ( $n=1377)$ & $p$ value \\
\hline Multidisciplinary conference & $1012(69.6)$ & $57(75.0)$ & $955(69.4)$ & 0.361 \\
\hline Non-monetary incentive for referral & $784(54.0)$ & $55(72.4)$ & $729(52.9)$ & 0.001 \\
\hline Automated notice system & $957(65.9)$ & $57(75.0)$ & $900(65.4)$ & 0.109 \\
\hline Patient education system & $1316(90.6)$ & 70 (92.1) & $1246(90.5)$ & 0.788 \\
\hline Patient brochure & $981(67.5)$ & $58(76.3)$ & $923(67.0)$ & 0.119 \\
\hline Heart failure clinic & $1158(79.7)$ & $62(81.6)$ & $1096(79.6)$ & 0.785 \\
\hline ICD check-up clinic & $1315(90.5)$ & $66(86.8)$ & $1249(90.7)$ & 0.359 \\
\hline Total hospital system score ${ }^{*}$ & $5.0(4.0-7.0)$ & $6.0(5.0-7.0)$ & $5.0(4.0-7.0)$ & 0.013 \\
\hline
\end{tabular}

ICD, implantable cardioverter defibrillator.

Values are presented as a median [01-03 quartiles (25th and 75th percentiles)] or number (\%).

${ }^{*}$ A sum of the number of applied systems, including multidisciplinary conference, non-monetary incentive for referral, automated notice system, patient education system, patient brochure, heart failure clinic, and ICD check-up clinic.

Table 3. Univariate and Multivariate Logistic Regression Analyses of Patient and System Score Factors Affecting ICD Implantation

\begin{tabular}{|c|c|c|c|c|}
\hline & \multicolumn{2}{|c|}{ Univariate } & \multicolumn{2}{|c|}{ Multivariate* } \\
\hline & Odds ratio $(95 \% \mathrm{CI})$ & $p$ value & Odds ratio (95\% CI) & $p$ value \\
\hline Age $<70$ & $1.92(1.19-3.08)$ & 0.007 & $2.14(1.30-3.53)$ & 0.003 \\
\hline PAOD & $0.63(0.40-1.00)$ & 0.049 & $0.55(0.34-0.91)$ & 0.019 \\
\hline NYHA class $\geq 3$ & $4.15(1.86-9.23)$ & $<0.001$ & 7.29 (2.97-17.87) & $<0.001$ \\
\hline LVEF $<25 \%$ & $1.64(0.95-2.85)$ & 0.076 & & \\
\hline \multicolumn{5}{|l|}{ Medication } \\
\hline ACEi/ARB & $2.71(1.16-6.31)$ & 0.021 & $1.95(0.80-4.77)$ & 0.141 \\
\hline Beta blocker & $2.18(1.03-4.59)$ & 0.041 & $1.93(0.89-4.22)$ & 0.098 \\
\hline Diuretics & $1.56(0.96-2.55)$ & 0.074 & & \\
\hline Antiarrhythmic agent & $2.65(1.21-5.78)$ & 0.014 & $3.77(1.66-8.60)$ & 0.002 \\
\hline Total hospital system score ${ }^{\dagger}$ & $1.17(1.01-1.35)$ & 0.038 & $1.28(1.10-1.50)$ & 0.002 \\
\hline
\end{tabular}

ACEi, angiotensin converting enzyme inhibitor; ARB, aldosterone receptor blocker; Cl, confidence interval; ICD, implantable cardioverter defibrillator; LVEF, left ventricular ejection fraction; NYHA, New York Heart Association; PAOD, peripheral arterial occlusive disease.

*Odds ratio was adjusted for age $<70$ years, presence of PAOD, NYHA functional class (III and IV), taking ACEi/ARB, beta blocker, and antiarrhythmic agent, and total hospital system score, ${ }^{\dagger} A$ sum of the number of applied systems, including multidisciplinary conference, non-monetary incentive for referral, automated notice system, patient education system, patient brochure, heart failure clinic, and ICD check-up clinic. 
we additionally evaluated ICD implantation rates in patients whose LVEF was lower than $35 \%$, and therein, the ICD implantation rate was $5.31 \%$. These centers have better established electrophysiology laboratories than relatively small hospitals, indicating that the implantation rate of PP ICD in community settings could be much lower. Previous studies explained that the discordant practice in PP ICD was largely influenced by referral failure from general cardiologists to electrophysiology cardiologists in the UK. ${ }^{30,31}$ Since health care systems differ among countries, a direct comparison of the results of the present study with those of other studies is impossible. However, the present study revealed that the application of hospital systems for referral pathway, such as a non-monetary incentive system for referral, was associated with high ICD implantation rates, and this result could indicate the importance of referral pathways for appropriate PP ICD implantation in ICM patients, in line with previous studies.

\section{Characteristics of patients with appropriate PP ICD}

Previous trials have described an underutilization of ICD implantation in women and ethnic minorities. ${ }^{32}$ However, the results of the present study showed no sex-based differences between the ICD and no-ICD groups. We did not evaluate ethnic factors because there is fundamentally no ethnic difference among people in Korea. Limited data are available about ICD implantation in older patients because several trials excluded patients 80 years or older. ${ }^{33,34}$ A previous questionnaire survey also revealed that physicians tended not to follow guidelines in patients who are older and have comorbidities. ${ }^{30}$ In accordance with previous studies, the present study revealed that age $<70$ years and less PAOD were factors associated with appropriate PP ICD implantation. Physicians may hesitate to refer older patients for ICD implantation due to limited evidence. Furthermore, since older patients and those with PAOD might have other comorbidities, physicians may have difficulty choosing additional procedures with consideration of the risks and benefits. A previous study reported that, among HF patients with indications for ICD, there was a higher ICD implantation rate in patients who were treated with guideline-based optimal medical therapy. ${ }^{21}$ However, the present study demonstrated that taking HF medications was not associated with appropriate ICD implantation. The present study revealed that taking antiarrhythmic agents and having a higher NYHA functional class (III, IV) independently affected appropriate ICD implantation. Patients with more severe symptoms or deteriorated cardiac function should be considered at high risk for future arrhythmic events.

\section{Systems for ICD implantation and characteristics of each center}

Previous studies have reported that underutilization of PP ICD implantation could be the result of a lack of knowledge and complex guideline criteria. Therefore, an automated, com- puterized screening system could help countries overcome those problems. ${ }^{30}$ In the present study, a total hospital system score and a non-monetary incentive for referral were associated with improved appropriate ICD implantation. An automated notice system might help physicians decrease the risk of overlooking ICD-eligible patients during follow up in outpatient clinics. A non-monetary incentive for referral can motivate physicians and could be an effective way to improve the referral pathway. The results of this study showed that a high rate of system application, regardless of composition, was a significant independent factor for ICD implantation. This result indicates that both system type and harmony might be important for improving PP ICD.

The present study showed that, although larger hospital had more systems for improving ICD implantation and more ICDs were implanted in large volume centers, the implantation rate was not significantly associated with hospital size. Previous studies have reported that barriers to the referral pathway and non-referral were the most common factors contributing to eligible patients not being treated with ICD. ${ }^{28,31,35}$ However, the present study revealed that the ICD implantation rates of each hospital did not differ according to referral rates. Referral rates in this study were assessed via questionnaires with multiple choice questions. Therefore, the cutoff for a referral rate of $30 \%$ in the analysis was not an exact determinant for a high or low referral rate. This could be the reason for the non-statistical significance between referral rate and ICD implantation rate. Instead, the number of applied hospital systems and the nonmonetary incentive for referral, which were designed for better screening and referral pathways, showed a beneficial influence on appropriate PP ICD treatment. This results could emphasize the need for better screening and referral pathways for appropriate PP ICD implantation. To our knowledge, this is the first study to investigate the usefulness of hospital systems for improving appropriate ICD implantation in multiple tertiary centers.

\section{Study limitations}

There are several limitations to this study. First, although it was prospective and enrolled a large population, the follow-up period (median 10 months) was relatively short. In Korea, patients usually visit the outpatient clinic every 6 months, so the follow-up period of this study could be inadequate for evaluating the benefit of new applied systems. Furthermore, ICD implantation rate could be underestimated with the short follow-up duration because there could be a delay in procedures for several reasons, even though physicians properly recommended PP-ICD according to set guidelines. Second, since some systems were usually applied together, analysis of the usefulness of each system was limited due to multicollinearity. We tried to correct for this limitation by using a new variable of total hospital system score. Third, the timing of the application of hospital factors varied, and the actual application 
of the systems to each patient could not be traced. This could obscure the effect of hospital systems. However, since most hospital factors were applied through established hospital systems and performed by physicians, we believed that a substantial portion of hospital factors would be applied to each patient.

\section{Conclusion}

PP ICD implantation for ICM is underused in Korea. Hospital factors appear to contribute to improving PP ICD implantation rates, suggesting that new screening and referral systems for ICM patients would help improve PP ICD implantation rates.

\section{ACKNOWLEDGEMENTS}

This study was supported by a research grant from Medtronics, Korea, and partially by the CMB-Yuhan research grant of Yonsei University College of Medicine (6-2019-0124).

\section{AUTHOR CONTRIBUTIONS}

Conceptualization: all authors. Data curation: all authors. Formal analysis: Jae-Hyuk Lee, Hee Tae Yu, Junbeom Park, and Boyoung Joung. Funding acquisition: Boyoung Joung. Investigation: all authors. Methodology: Jae-Hyuk Lee, Hee Tae Yu, Junbeom Park, and Boyoung Joung. Project administration: all authors. Resources: all authors. Software: Jae-Hyuk Lee, Hee Tae Yu, Junbeom Park, and Boyoung Joung. Supervision: all authors. Validation: Jae-Hyuk Lee, Hee Tae Yu, Junbeom Park, and Boyoung Joung. Visualization: JaeHyuk Lee, Hee Tae Yu, Junbeom Park, and Boyoung Joung. Writingoriginal draft: Jae-Hyuk Lee, Hee Tae Yu, and Boyoung Joung. Writing-review \& editing: Jae-Hyuk Lee, Hee Tae Yu, Junbeom Park, and Boyoung Joung. Approval of final manuscript: all authors.

\section{ORCID iDs}

$\begin{array}{ll}\text { Jae-Hyuk Lee } & \text { https://orcid.org/0000-0002-1170-7111 } \\ \text { Hee Tae Yu } & \text { https://orcid.org/0000-0002-6835-4759 } \\ \text { Il-Young Oh } & \text { https://orcid.org/0000-0002-5584-605X } \\ \text { Eue-Keun Choi } & \text { https://orcid.org/0000-0002-0411-6372 } \\ \text { Jung-Hoon Sung } & \text { https://orcid.org/0000-0003-3515-5283 } \\ \text { Young Soo Lee } & \text { https://orcid.org/0000-0002-8229-8300 } \\ \text { Jong-Youn Kim } & \text { https://orcid.org/0000-0001-7040-8771 } \\ \text { Yongsoo Baek } & \text { https://orcid.org/0000-0002-6086-0446 } \\ \text { Junbeom Park } & \text { https://orcid.org/0000-0003-2192-9401 } \\ \text { Boyoung Joung } & \text { https://orcid.org/0000-0001-9036-7225 }\end{array}$

\section{REFERENCES}

1. Zipes DP, Wellens HJ. Sudden cardiac death. Circulation 1998;98: 2334-51.

2. Uretsky BF, Sheahan RG. Primary prevention of sudden cardiac death in heart failure: will the solution be shocking? J Am Coll Cardiol 1997;30:1589-97.

3. Moss AJ, Hall WJ, Cannom DS, Daubert JP, Higgins SL, Klein H, et al. Improved survival with an implanted defibrillator in patients with coronary disease at high risk for ventricular arrhythmia. Multicenter Automatic Defibrillator Implantation Trial Investigators.
N Engl J Med 1996;335:1933-40.

4. Moss AJ, Zareba W, Hall WJ, Klein H, Wilber DJ, Cannom DS, et al. Prophylactic implantation of a defibrillator in patients with myocardial infarction and reduced ejection fraction. N Engl J Med 2002; 346:877-83.

5. Bänsch D, Antz M, Boczor S, Volkmer M, Tebbenjohanns J, Seidl $\mathrm{K}$, et al. Primary prevention of sudden cardiac death in idiopathic dilated cardiomyopathy: the Cardiomyopathy Trial (CAT). Circulation 2002;105:1453-8.

6. Kuck KH, Cappato R, Siebels J, Rüppel R. Randomized comparison of antiarrhythmic drug therapy with implantable defibrillators in patients resuscitated from cardiac arrest: the Cardiac Arrest Study Hamburg (CASH). Circulation 2000;102:748-54.

7. Connolly SJ, Gent M, Roberts RS, Dorian P, Roy D, Sheldon RS, et al. Canadian implantable defibrillator study (CIDS): a randomized trial of the implantable cardioverter defibrillator against amiodarone. Circulation 2000;101:1297-302.

8. Connolly SJ, Hallstrom AP, Cappato R, Schron EB, Kuck KH, Zipes DP, et al. Meta-analysis of the implantable cardioverter defibrillator secondary prevention trials. AVID, CASH and CIDS studies. Antiarrhythmics vs Implantable Defibrillator study. Cardiac Arrest Study Hamburg. Canadian Implantable Defibrillator Study. Eur Heart J 2000;21:2071-8.

9. Antiarrhythmics versus Implantable Defibrillators (AVID) Investigators. A comparison of antiarrhythmic-drug therapy with implantable defibrillators in patients resuscitated from near-fatal ventricular arrhythmias. N Engl J Med 1997;337:1576-83.

10. Ponikowski P, Voors AA, Anker SD, Bueno H, Cleland JGF, Coats AJS, et al. 2016 ESC Guidelines for the diagnosis and treatment of acute and chronic heart failure: The Task Force for the diagnosis and treatment of acute and chronic heart failure of the European Society of Cardiology (ESC) Developed with the special contribution of the Heart Failure Association (HFA) of the ESC. Eur Heart J 2016;37:2129-200.

11. Priori SG, Blomström-Lundqvist C. 2015 European Society of Cardiology Guidelines for the management of patients with ventricular arrhythmias and the prevention of sudden cardiac death summarized by co-chairs. Eur Heart J 2015;36:2757-9.

12. Yancy CW, Jessup M, Bozkurt B, Butler J, Casey DE Jr, Drazner MH, et al. 2013 ACCF/AHA guideline for the management of heart failure: a report of the American College of Cardiology Foundation/ American Heart Association Task Force on Practice Guidelines. J Am Coll Cardiol 2013;62:e147-239.

13. Yancy CW, Jessup M, Bozkurt B, Butler J, Casey DE Jr, Colvin MM, et al. 2017 ACC/AHA/HFSA Focused Update of the 2013 ACCF/ AHA Guideline for the Management of Heart Failure: A Report of the American College of Cardiology/American Heart Association Task Force on Clinical Practice Guidelines and the Heart Failure Society of America. J Am Coll Cardiol 2017;70:776-803.

14. Bardy GH, Lee KL, Mark DB, Poole JE, Packer DL, Boineau R, et al. Amiodarone or an implantable cardioverter-defibrillator for congestive heart failure. N Engl J Med 2005;352:225-37.

15. Buxton AE, Lee KL, Fisher JD, Josephson ME, Prystowsky EN, Hafley G. A randomized study of the prevention of sudden death in patients with coronary artery disease. Multicenter Unsustained Tachycardia Trial Investigators. N Engl J Med 1999;341:1882-90.

16. Kadish A, Dyer A, Daubert JP, Quigg R, Estes NA, Anderson KP, et al. Prophylactic defibrillator implantation in patients with nonischemic dilated cardiomyopathy. N Engl J Med 2004;350:2151-8.

17. Zhang S, Fan X, Lin N, Lau CP, Nair M, Yuniadi Y, et al. APHRS white book. 4th ed. Singapore: Asia Pacific Hear Rhythm Society; 2016.

18. Williams SC, Schmaltz SP, Morton DJ, Koss RG, Loeb JM. Quality 
of care in U.S. hospitals as reflected by standardized measures, 2002-2004. N Engl J Med 2005;353:255-64.

19. Lee DS, Tu JV, Juurlink DN, Alter DA, Ko DT, Austin PC, et al. Risktreatment mismatch in the pharmacotherapy of heart failure. JAMA 2005;294:1240-7.

20. Fonarow GC, Yancy CW, Heywood JT; ADHERE Scientific Advisory Committee, Study Group, and Investigators. Adherence to heart failure quality-of-care indicators in US hospitals: analysis of the ADHERE Registry. Arch Intern Med 2005;165:1469-77.

21. Shah B, Hernandez AF, Liang L, Al-Khatib SM, Yancy CW, Fonarow GC, et al. Hospital variation and characteristics of implantable cardioverter-defibrillator use in patients with heart failure: data from the GWTG-HF (Get With The Guidelines-Heart Failure) registry. J Am Coll Cardiol 2009;53:416-22.

22. Piccini JP, Hernandez AF, Dai D, Thomas KL, Lewis WR, Yancy CW, et al. Use of cardiac resynchronization therapy in patients hospitalized with heart failure. Circulation 2008;118:926-33.

23. Stafford RS, Radley DC. The underutilization of cardiac medications of proven benefit, 1990 to 2002. J Am Coll Cardiol 2003;41:5661.

24. Fonarow GC, Yancy CW, Albert NM, Curtis AB, Stough WG, Gheorghiade $\mathrm{M}$, et al. Heart failure care in the outpatient cardiology practice setting: findings from IMPROVE HF. Circ Heart Fail 2008; 1:98-106.

25. Schrage B, Uijl A, Benson L, Westermann D, Ståhlberg M, Stolfo $\mathrm{D}$, et al. Association between use of primary-prevention implantable cardioverter-defibrillators and mortality in patients with heart failure: a prospective propensity score-matched analysis from the swedish heart failure registry. Circulation 2019;140: 1530-9.

26. Ziaeian B, Zhang Y, Albert NM, Curtis AB, Gheorghiade M, Heywood JT, et al. Clinical effectiveness of CRT and ICD therapy in heart failure patients by racial/ethnic classification: insights from the IMPROVE HF registry. J Am Coll Cardiol 2014;64:797-807.
27. Køber L, Thune JJ, Nielsen JC, Haarbo J, Videbæk L, Korup E, et al. Defibrillator implantation in patients with nonischemic systolic heart failure. N Engl J Med 2016;375:1221-30.

28. Bradfield J, Warner A, Bersohn MM. Low referral rate for prophylactic implantation of cardioverter-defibrillators in a tertiary care medical center. Pacing Clin Electrophysiol 2009;32 Suppl 1:S194-7.

29. MacDonald MR, Tay WT, Teng TK, Anand I, Ling LH, Yap J, et al. Regional variation of mortality in heart failure with reduced and preserved ejection fraction across Asia: outcomes in the ASIANHF registry. J Am Heart Assoc 2020;9:e012199.

30. Sadarmin PP, Wong KC, Rajappan K, Bashir Y, Betts TR. Questionnaire survey of cardiologists' knowledge, attitudes, and guideline application of implantable cardioverter defibrillator therapy. Pacing Clin Electrophysiol 2012;35:672-80.

31. Castellanos JM, Smith LM, Varosy PD, Dehlendorf C, Marcus GM. Referring physicians' discordance with the primary prevention implantable cardioverter-defibrillator guidelines: a national survey. Heart Rhythm 2012;9:874-81.

32. Curtis LH, Al-Khatib SM, Shea AM, Hammill BG, Hernandez AF, Schulman KA. Sex differences in the use of implantable cardioverter-defibrillators for primary and secondary prevention of sudden cardiac death. JAMA 2007;298:1517-24.

33. Swindle JP, Rich MW, McCann P, Burroughs TE, Hauptman PJ. Implantable cardiac device procedures in older patients: use and in-hospital outcomes. Arch Intern Med 2010;170:631-7.

34. Heiat A, Gross CP, Krumholz HM. Representation of the elderly, women, and minorities in heart failure clinical trials. Arch Intern Med 2002;162:1682-8.

35. Sadarmin PP, Wong KC, Rajappan K, Bashir Y, Betts TR. Barriers to patients eligible for screening investigations and insertion of primary prevention implantable cardioverter defibrillators. Europace 2014;16:1575-9. 